\title{
Development of Intranasal Chitosan-Based Drug Delivery Containing Meloxicam ${ }^{\dagger}$
}

\author{
Patrícia Varga *, Rita Ambrus, Piroska Szabó-Révész and Csilla Bartos \\ Institute of Pharmaceutical Technology and Regulatory Affairs, Faculty of Pharmacy, University of Szeged, \\ Szeged, Hungary; ambrus.rita@szte.hu (R.A.); revesz@pharm.u-szeged.hu (P.S.-R.); \\ bartoscsilla@pharm.u-szeged.hu (C.B.) \\ * Correspondence: varga.patricia@szte.hu \\ + Presented at the 1st International Electronic Conference on Pharmaceutics, 1-15 December 2020; Available \\ online: https://iecp2020.sciforum.net/.
}

Received: date; Accepted: date; Published: date

\begin{abstract}
Chitosan is getting growing attention to increase the bioavailability of active pharmaceutical ingredients (APIs) and achieve controlled drug delivery. Through the nasal epithelium, the API absorption is rapid, which is beneficial in relieving acute pain, so intranasally administered meloxicam (MEL) could attain a rapid analgesic effect. The aims of our work were to develop spray-dried cross-linked and non-cross-linked chitosan-based drug delivery systems administrated for the intranasal route, and to optimize the spray-drying process parameters and the composition. The appropriate process parameters (inlet air temperature, pump rate) were determined based on the particle size distribution and morphology of drug-free chitosan particles. MEL-containing samples were prepared using different amounts of sodium tripolyphosphate (TPP). The micrometric properties, structural characterization and in vitro drug release were studied. Spray drying resulted in micronized chitosan particles regardless of the process parameters. The particle size of API-containing samples suited the requirements of intranasal powders, showed nearly spherical habit and MEL was present in a molecularly dispersed state in them. The highest MEL amount dissolved from the non-cross-linked MEL-containing sample. Our results indicate that spray-dried MEL-containing chitosan microparticles may be recommended for the development of a novel drug delivery system to decrease acute pain or enhance analgesia.
\end{abstract}

Keywords: chitosan; nasal meloxicam; microparticles; spray drying; sodium tripolyphosphate

\section{Introduction}

In the last decades, polymer-based drug delivery systems have received great attention, as they are suitable for increasing the bioavailability of compounds with poor water solubility. The active pharmaceutical ingredient (API) is often molecularly dispersed in them, which results in faster drug dissolution and absorption [1].

Chitosan is a semi-synthetic cationic polymer, that is biocompatible and is capable of enhancing permeation because of its interaction between the proteins that are associated with the epithelial tight junctions [2]. Chitosan has mucoadhesive properties as well. It forms an ionic bond with the negatively charged surface of the mucus, which can be very useful in the case of nasal drug administration because as a result of the rapid mucociliary clearance, the residence time of the API is short in the nasal cavity $[3,4]$. Due to its advantageous properties, it is getting growing attention in pharmaceutical technology studies as a matrix-forming material for controlled drug-delivering [5].

Nasal mucosa as an alternative drug delivery route has many therapeutic advantages: because of the large surface and high vascularization of the epithelium, drug absorption is rapid, and it avoids the first-pass hepatic metabolism. It also provides an opportunity to deliver API to the Proceedings 2020, 4, $\mathrm{x}$; doi: FOR PEER REVIEW www.mdpi.com/journal/proceedings 
systemic circulation or the central nervous system in a non-invasive, painless way, and the sterility of the preparations is not required. The use of powder-based formulations in the nasal cavity is more preferred than liquid ones, since-according to the mucociliary clearance- they get cleared slower from the nasal cavity and their physical stability is also better [6].

Meloxicam (MEL) is a nonsteroidal anti-inflammatory poorly water-soluble drug which could be administered intranasally in order to attain an analgesic effect. WHO (World Health Organization) developed the model to guide the management of different pain. NSAIDs are recommended for acute pain therapy or are co-administered with other pain killer as adjuvants to enhance analgesia [7].

The aim of this work was to prepare spray-dried drug-free chitosan particles while optimizing the process parameters and meloxicam-containing particles to determine the appropiate composition of the formulation including the determination of the right amount of cross-linking agent (sodium tripolyphosphate, TPP) to develop a drug delivery system wich is suitable for application in the pain therapy.

\section{Experiments}

\subsection{Materials}

Meloxicam (MEL) was from EGIS Ltd. (Budapest, Hungary). Low molecular weight chitosan was obtained from Sigma Aldrich (Sigma Aldrich Co. LLC, St. Louis, MO, USA), TPP was purchased from Alfa Aeasar Co. (Alfa Aeasar GmbH \& Co. KG, Karlsruhe, Germany). Dimethyl sulfoxide was from VWR Chemicals BDH Prolabo and Acetic acid was from Molar Chemicals Ltd. (Budapest, Hungary).

\subsection{Methods}

\subsubsection{Preparation of Spray-Dried Products}

For optimizing the process parameteres, $1 \%$ chitosan solution was prepared by using $1 \%$ acetic acid solution as solvent. It was spray-dried using Büchi Mini Dryer B-191 (Switzerland). Inlet air temperature and pump rate were varied between 90,120 and $150{ }^{\circ} \mathrm{C}$ and 5, 10 and $15 \mathrm{~mL} / \mathrm{min}$ (Table 1). Aspirator capacity was $75 \%$. Hereinafter, to optimize the composition of the formulation, $3.75 \mathrm{~mL}$ $4 \%$ MEL solution using dimethyl sulfoxide (DMSO) as solvent was emulsified with $50 \mathrm{~mL}$ of $1 \%$ chitosan solution containing either 0,1 or $2 \mathrm{~mL}$ of $1 \%$ aqueous solution of TPP (Table 2).

Table 1. Spray-drying process parameters.

\begin{tabular}{cccc}
\hline Inlet air temperature $\left[{ }^{\circ} \mathrm{C}\right]$ & 90 & 120 & 150 \\
Pump rate $[\mathrm{mL} / \mathrm{min}]$ & 5 & 10 & 15 \\
\hline
\end{tabular}

Table 2. Composition of solutions for spray-drying.

\begin{tabular}{ccccccc}
\hline $\mathbf{1 \%}$ chitosan solution $[\mathrm{mL}]$ & 50 & 50 & 50 & 50 & 50 & 50 \\
$\mathbf{1 \%}$ aqueous TPP solution $[\mathrm{mL}]$ & - & 1 & 2 & - & 1 & 2 \\
$\mathbf{4} \%$ MEL-DMSO-solution $[\mathrm{mL}]$ & - & - & - & 3.75 & 3.75 & 3.75 \\
\hline
\end{tabular}

\subsubsection{Size Distribution by Laser Diffraction}

The volume particle-size distribution was measured by laser diffraction (Malvern Mastersizer Sirocco 2000, Malvern Instruments Ltd., UK). Approximately $1 \mathrm{~g}$ of spray-dried product was tested in one measurement, and 3 parallel measurements were made each time at 3 bar pressure and $75 \%$ frequency measurement parameters. D10, D50 and D90 were determined, these show the maximum diameter of the particles below which 10, 50 and $90 \%$ of the sample volume exists. 


\subsubsection{Scanning Electron Microscopy (SEM)}

To examine the shape and surface characteristics of the samples, SEM (Hitachi S4700, Hitachi Scientific Ltd., Tokyo, Japan) was used. Under an argon atmosphere, the samples were coated with gold-palladium by using a sputter coating apparatus in a high-vacuum evaporator. The air pressure was $1.3-13 \mathrm{Mpa}$ and the samples were examined at $15 \mathrm{kV}$ and $10 \mu \mathrm{A}$.

\subsubsection{Differential Scanning Calorimetry (DSC)}

The thermal analysis of the samples were carried out with a Mettler Toledo DSC 821e (Germany) system with the STARe program V9.1 (Mettler Inc., Schwerzenbach, Switzerland). Approximately 2-5 mg of samples were examined in the temperature range between $25^{\circ} \mathrm{C}$ and 300 ${ }^{\circ} \mathrm{C}$. The heating rate was set to $10{ }^{\circ} \mathrm{C} \cdot \mathrm{min}^{-1}$. Argon was used as carrier gas at a flow rate of $10 \mathrm{~L} \cdot \mathrm{h}^{-1}$ during the DSC investigation. Physical mixtures of chitosan, MEL and TPP in the same mass ratio as used to prepare the spray-dried products were applied as control samples. The components were mixed in a Turbula mixer (Turbula WAB, Systems Schatz, Switzerland) at $50 \mathrm{rpm}$ for $10 \mathrm{~min}$.

\subsubsection{X-ray Powder Diffraction (XRPD)}

The physical state of the MEL in the different samples were evaluated by XRPD with a Bruker D8 Advance diffractometer (Bruker AXS GmbH, Karlsruhe, Germany) system, where the tube anode was $\mathrm{Cu}$ with $\mathrm{K} \alpha=1.5406 \AA$. The samples were scanned with a tube voltage of $40 \mathrm{kV}$ and a tube current of $40 \mathrm{~mA}$. The instrument was calibrated by using Si. Physical mixtures of chitosan, MEL and TPP in the same mass ratio as used to prepare the spray-dried products were applied as control samples, prepared as before.

\subsubsection{In Vitro Dissolution}

The dissolution of MEL was determined according to the European Pharmacopoeia (6th Edition) paddle method (USP dissolution apparatus, type II Pharma Test, Heinburg, Germany). 100 mg samples were dispersed in $50 \mathrm{~mL}$ of phosphate buffer solution ( $\mathrm{pH} 5.6 \pm 0.1$ ) at $30 \pm 0.5^{\circ} \mathrm{C}$, used as a dissolution medium and the rotation speed of the paddles was $100 \mathrm{rpm}$. At predetermined intervals, the amount of dissolved MEL was determined by spectrophotometry (UNICAM UV/Vis Spectrometer, Germany) at $364 \mathrm{~nm}$.

\section{Results}

\subsection{Particle Size Distribution}

The aim was the spray drying process to be as cost-effective and fast as possibble during the sample preparation. Since, the inlet air temperature and pump rate did not have an effect on the size distributions of chitosan particles and they met the size criterion of nasal powders $(<40 \mu \mathrm{m})[8]$ (Table 3), we chose the mild $90{ }^{\circ} \mathrm{C}$ inlet air temparature and the relatively quick $10 \mathrm{~mL} / \mathrm{min}$ pump rate to prepare the MEL- and TPP-containing particles. TPP on its own did not have an effect on the sizes of chitosan particles however, in case of the MEL-containig particles, size increasing was noticable especially when $2 \mathrm{~mL}$ of TPP-solution was added. Overall, the particle size of every sample suited the requirements $(<40 \mu \mathrm{m})$ (Table 4$)$.

Table 3. Optimization of the process parameters.

\begin{tabular}{cccccccccc}
\hline Sample & 1 & 2 & 3 & 4 & 5 & 6 & 7 & 8 & 9 \\
\hline Inlet air temperature $\left[{ }^{\circ} \mathrm{C}\right]$ & 90 & 120 & 150 & 90 & 120 & 150 & 90 & 120 & 150 \\
Pump rate $[\mathrm{mL} / \mathrm{min}]$ & 5 & 5 & 5 & 10 & 10 & 10 & 15 & 15 & 15 \\
Aspirator $[\%]$ & 75 & 75 & 75 & 75 & 75 & 75 & 75 & 75 & 75 \\
D10 $[\mu \mathrm{m}]$ & 1.044 & 1.446 & 1.529 & 1.176 & 1.255 & 1.241 & 1.115 & 1.274 & 1.369 \\
D50 $[\mu \mathrm{m}]$ & 2.374 & 3.669 & 3.736 & 2.466 & 2.815 & 2.701 & 2.263 & 2.629 & 2.889 \\
\hline
\end{tabular}




\begin{tabular}{llllllllll}
\hline $\mathrm{D} 90[\mu \mathrm{m}]$ & 5.216 & 8.535 & 9.032 & 5.102 & 5.903 & 5.519 & 4.744 & 5.195 & 5.664 \\
\hline
\end{tabular}

Table 4. Optimization of the composition.

\begin{tabular}{ccccccc}
\hline Sample & 4 & 10 & 11 & 12 & 13 & 14 \\
\hline Inlet air temperature $\left[{ }^{\circ} \mathbf{C}\right]$ & 90 & 90 & 90 & 90 & 90 & 90 \\
Pump rate $[\mathbf{m L} / \mathbf{m i n}]$ & 10 & 10 & 10 & 10 & 10 & 10 \\
Aspirator $[\%]$ & 75 & 75 & 75 & 75 & 75 & 75 \\
$\mathbf{1 \%}$ aqueous TPP-solution $[\mathrm{mL}]$ & - & 1 & 2 & - & 1 & 2 \\
MEL-DMSO-solution $[\mathrm{mL}]$ & - & - & - & 3.75 & 3.75 & 3.75 \\
D10 $[\boldsymbol{\mu m}]$ & 1.176 & 1.243 & 1.103 & 1.269 & 1.426 & 1.617 \\
D50 $[\mu \mathrm{m}]$ & 2.466 & 2.595 & 2.419 & 2.965 & 3.757 & 5.575 \\
D90 $[\mu \mathrm{m}]$ & 5.102 & 5.234 & 5.138 & 7.211 & 9.461 & 15.995 \\
\hline
\end{tabular}

\subsection{Morphology of the Samples}

The SEM images provided an indication of the morphology of microparticles. Products formulated without TPP (Sample 4 and 12) were compared with products containing $2 \mathrm{~mL}$ of TPP solution (Sample 11 and 14). Drug free particles (Sample 4, 11) had a hollow structure meanwhile, nearly spherical morphology was observed in case of MEL-containing samples (Sample 12, 14) regardless of TPP-content (Figure 1).
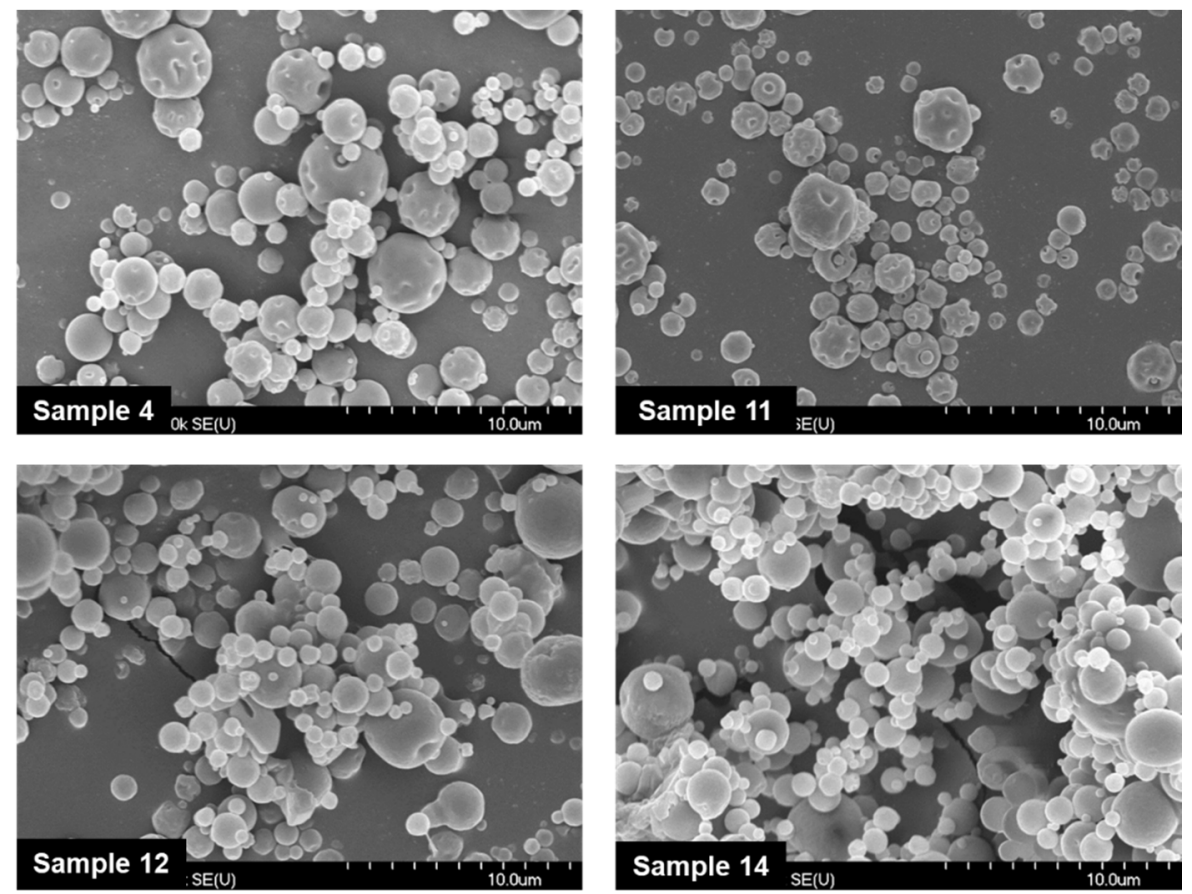

Figure 1. SEM pictures of spray-dried samples.

\subsection{Thermoanalytical Behaviors}

In the DSC curves (Figure 2), sharp melting points could be observed in case of the physical mixtures which indicated that raw MEL was crystalline. The endothermic peaks at around $256{ }^{\circ} \mathrm{C}$ corresponded to the melting point of MEL. The characteristic endothermic peaks of crystalline MEL disapeared in case of the spray-dried products except the non-cross-linked sample (Sample 12), in that curve the reduced intensity peak referred to the presence of crystalline fraction of MEL. 


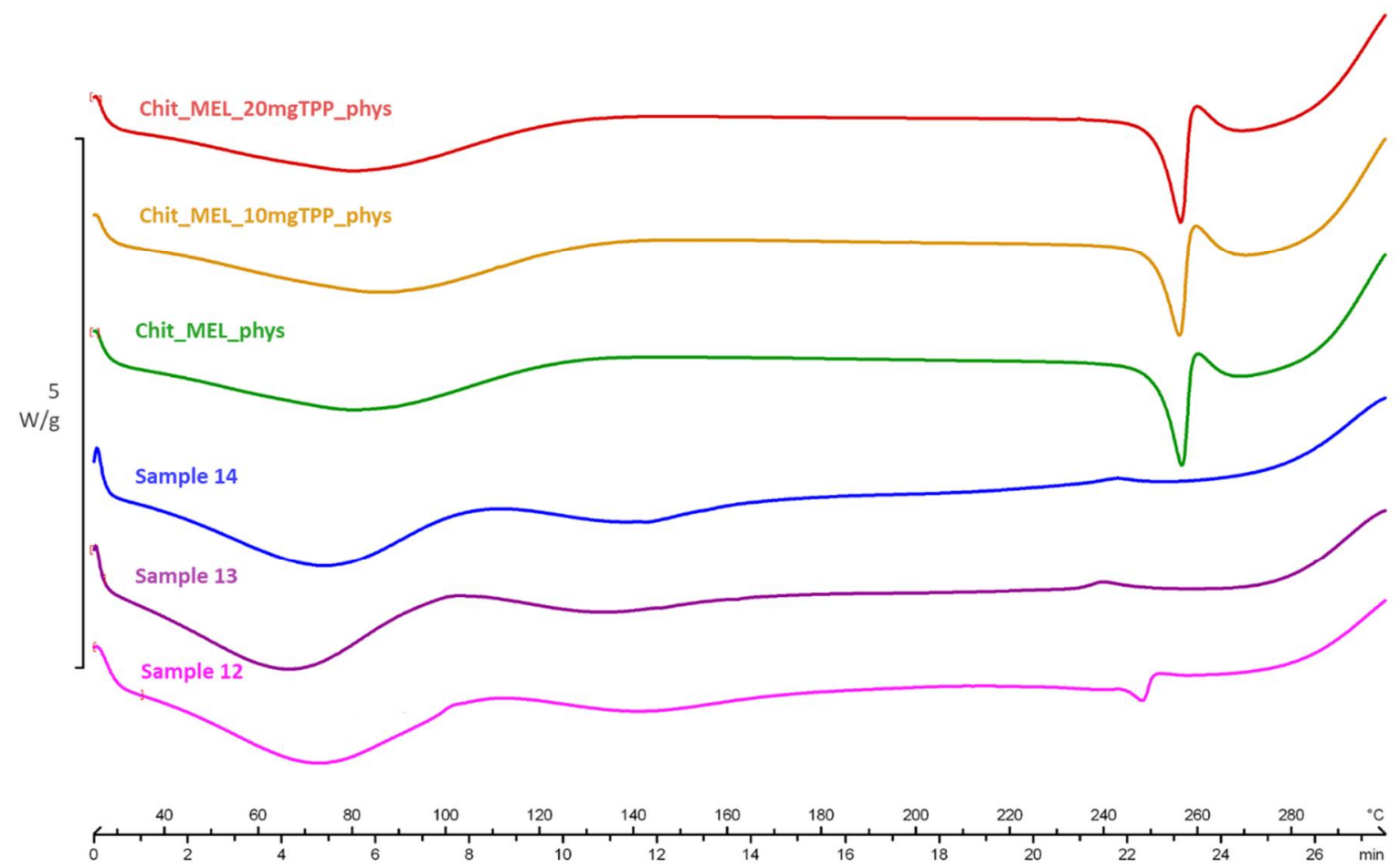

Figure 2. DSC curves of physical mixtures containing chitosan, MEL and TPP (Chit_MEL_20 mgTPP, Chit_MEL_10 mgTPP, Chit_MEL) and spray-dried samples.

\subsection{Structural Characterization by XRPD}

Raw MEL was crystalline in the physical mixtures, characteristic peaks apperared at 13.22, 15.06 and $25.7^{\circ}(2 \Theta)$. The diffractograms of the spray-dried samples indicated the presence of some crystalline fraction of MEL with the decrease of TPP concentration (Figure 3).

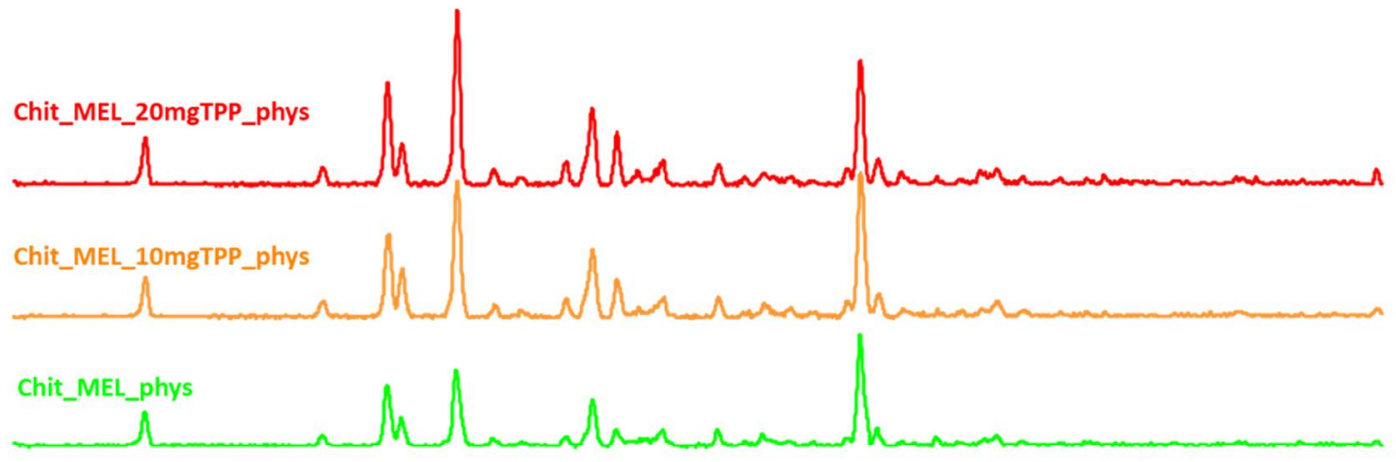

Sample 14

Sample 13

Sample 12

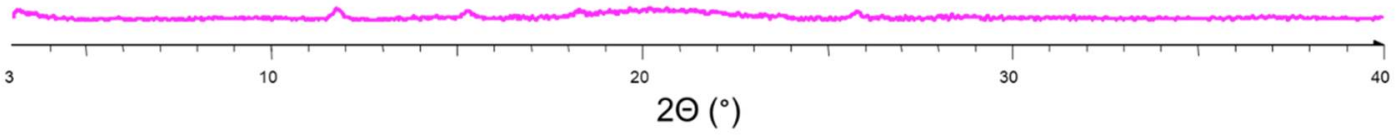

Figure 3. XRPD patterns of physical mixtures and spray-dried samples. 


\subsection{In Vitro Dissolution Study}

Minimal drug release was observed in case of the poorly water soluble raw MEL at nasal conditions. Samples revealed controlled drug release with a fast initial dissolution within 15 min. The largest amount of MEL released from the non-cross-linked Sample 12, whereby approximately 95\% of MEL dissolved during $1 \mathrm{~h}$. (Figure 4).

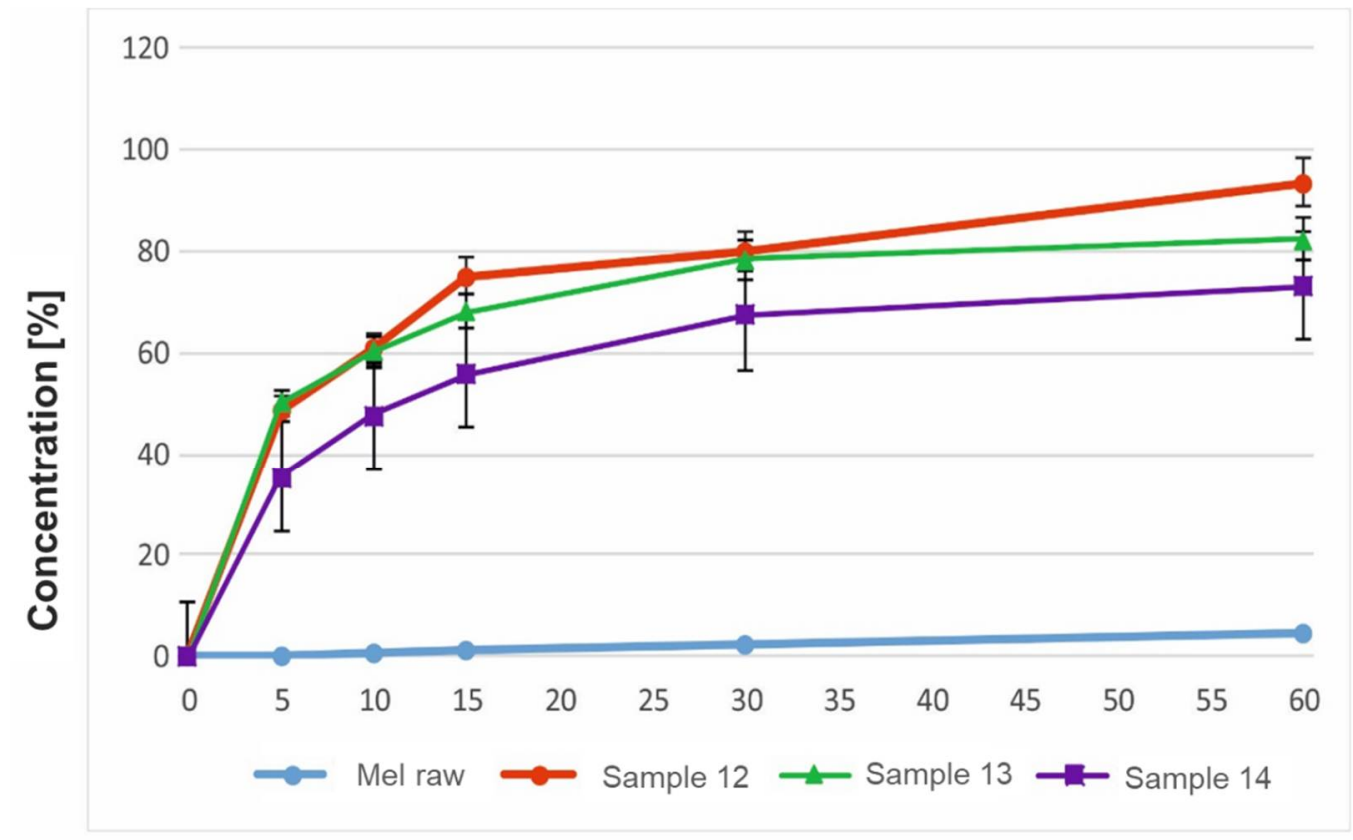

Time [min]

Figure 4. In vitro dissolution profiles of MEL from different samples.

\section{Discussion}

During this work, spray-dried chitosan microparticles were prepared to study the effect of the spray drying process parameters on the micrometric properties of the particles in the interest of optimizing the inlet air temperature and pump rate. The inlet air temperature and pump rate did not have an effect on the particle size distribution and morphology, therefore $90^{\circ} \mathrm{C}$ and $10 \mathrm{~mL} / \mathrm{min}$ were chosen. Hereinafter, applying these parameters, MEL-containing samples were prepared adding different amounts of TPP solutions and the samples were examined to determine the possibly appropriet composition of a nasal powder intended for pain relieving.

Micrometric properties are important because they have an effect on the deposition of powder in the nasal cavity [6]. Based on the results, the size of spray-dried MEL containing particles increased compared to the drug-free particles, however, they were set according to the requirements of nasal dosage forms and they had a spherical habit.

It can be stated that in the spray-dried samples, MEL was primarily in a molecularly dispersed state, although in case of the non-cross-linked samples a small crystalline fraction of MEL was observed.

According to the in vitro dissolution study, the amount of dissolved MEL was decreased by increasing the concentration of TPP. It can be explained by the formed cross-links so that chitosan retained MEL from dissolution. For all three samples, the initial rapid dissolution was followed by slowing drug release.

\section{Conclusions}

The aim of this research was to optimize the parameters of spray drying and investigate different compositions in order to develop chitosan-based microparticles for nasal application. 
MEL-containing drug delivery systems were produced and studied. Thanks to the mucoadhesive and permeability-enhancer features of chitosan and the fast and continuous dissolution of amorphous MEL, developed microparticles prepared by spray drying may be recommended for relieving acute pain or enhance analgesia through the nasal mucosa.

Author Contributions: C.B., R.A. and P.S.-R. conceived and designed the experiments; C.B. and P.V. performed the experiments; C.B. and P.V. analyzed the data; P.V., C.B and R.A. wrote the paper. All authors have read and agreed to the published version of the manuscript.

Acknowledgments: This work was supported by the Ministry of Human Capacities, Hungary grant (20391-3/2018/FEKUSTRAT) and 2.2.1-15-2016-00007 Project.

Conflicts of Interest: The authors declare no conflict of interest. The founding sponsors had no role in the design of the study; in the collection, analyses, or interpretation of data; in the writing of the manuscript, and in the decision to publish the results.

\section{Abbreviations}

The following abbreviations are used in this manuscript:

API: active pharmaceutical ingredient

MEL: meloxicam

TPP: sodium tripolyphosphate

DMSO: dimethyl sulfoxide

WHO: World Health Organization

\section{References}

1. Liu, J.; Grohganz, H.; Rades, T. Influence of polymer addition on the amorphization, dissolution and physical stability of co-amorphous systems. Int. J. Pharm. 2020, 588, 119768, doi:10.1016/j.ijpharm.2020.119768.

2. Illum, L. Nasal drug delivery-Possibilities, problems and solutions. J. Control. Release 2003, 87, 187-198, doi:10.1016/S0168-3659(02)00363-2.

3. Bravo-Osuna, I.; Vauthier, C.; Farabollini, A.; Palmieri, G.F.; Ponchel, G. Mucoadhesion mechanism of chitosan and thiolated chitosan-poly(isobutyl cyanoacrylate) core-shell nanoparticles. Biomaterials 2007, 28, 2233-2243, doi:10.1016/j.biomaterials.2007.01.005.

4. Inoue, D.; Tanaka, A.; Kimura, S.; Kiriyama, A.; Katsumi, H.; Yamamoto, A.; Ogawara, K.; Kimura, T.; Higaki, K.; Yutani, R.; et al. The relationship between in vivo nasal drug clearance and in vitro nasal mucociliary clearance: Application to the prediction of nasal drug absorption. Eur. J. Pharm. Sci. 2018, 117, 21-26, doi:10.1016/j.ejps.2018.01.032.

5. Kašpar, O.; Tokárová, V.; Nyanhongo, G.S.; Gübitz, G.; Štěpánek, F. Effect of cross-linking method on the activity of spray-dried chitosan microparticles with immobilized laccase. Food Bioprod. Process. 2013, 91, 525-533, doi:10.1016/j.fbp.2013.06.001.

6. Alhalaweh, A.; Andersson, S.; Velaga, S.P. Preparation of zolmitriptan-chitosan microparticles by spray drying for nasal delivery. Eur. J. Pharm. Sci. 2009, 38, 206-214, doi:10.1016/j.ejps.2009.07.003.

7. Neeta, K. WHO Normative Guidelines on Pain Management-Report of a Delphi Study to Determine the Need for Guidelines and to Identify the Number and Topics of Guidelines that Should Be Developed by WHO; 2007.

8. Kiss, T.; Alapi, T.; Varga, G.; Bartos, C.; Ambrus, R.; Szabó-Révész, P.; Katona, G. Interaction Studies Between Levodopa and Different Excipients to Develop Coground Binary Mixtures for Intranasal Application. J. Pharm. Sci. 2019, 108, 2552-2560, doi:10.1016/j.xphs.2019.03.005.

Publisher's Note: MDPI stays neutral with regard to jurisdictional claims in published maps and institutional affiliations.

(C) 2020 by the authors. Submitted for possible open access publication under the terms and conditions of the Creative Commons Attribution (CC BY) license (http://creativecommons.org/licenses/by/4.0/). 